\title{
Dynamic Modeling and Analysis of an Industrial Gas Suspension Absorber for Flue Gas Desulfurization
}

\author{
Stefano Cignitti ${ }^{1} \cdot$ Seyed Soheil Mansouri ${ }^{1}$ - Mauricio Sales-Cruz ${ }^{3}$ - Flemming Jensen ${ }^{2}$. \\ Jakob Kjøbsted Huusom ${ }^{1}$
}

Received: 17 July 2015 /Revised: 9 October 2015 / Accepted: 11 November 2015 / Published online: 7 December 2015

(C) Springer International Publishing Switzerland 2015

\begin{abstract}
In this work, semidry desulfurization of flue gas using a gas suspension absorber (GSA) is studied. A simple dynamic model which can properly represent the GSA was developed. In order to model the reaction kinetics, an empirical reaction rate expression was introduced. The reaction rate expression parameters were fitted to operational data from a real cement plant. A detailed statistical analysis of the parameter estimation procedure was performed, and the confidence intervals for estimated kinetic parameters were calculated. The model and reaction rate expression prediction ability was tested using another plant data set. It was verified that in spite of the simplicity of the model, very good prediction of industrial behavior was obtained. Furthermore, the dynamic analysis of the system was performed by carrying out open-loop and closed-loop simulations to verify plant dynamics. Therefore, a simple dynamic model with a reaction rate expression that is simple and efficient to use to predict the dynamics of GSA process was proposed in this work.
\end{abstract}

Keywords Gas suspension absorber · Desulfurization kinetics $\cdot$ Dynamic modeling $\cdot$ Simulation $\cdot$ Control

Jakob Kjøbsted Huusom

jkh@kt.dtu.dk

1 Department of Chemical and Biochemical Engineering, Technical University of Denmark, Søltofts Plads, Building 229,

Lyngby, Denmark

2 Airtech-Air Pollution Control, FLSmidth A/S, Ramsingsvej 30, Valby, Denmark

3 Departamento de Procesos y Tecnología, Universidad Autónoma Metropolitana-Cuajimalpa, Artificios No. 40, C.P. 01120 México, D.F., Mexico

\section{Introduction}

Many of the fossil fuels used in industry contain compounds that upon combustion emit substances [1], such as sulfur oxides [2], nitrogen oxides, other acids, and mercury that are harmful to the environment [3]. The amount of harmful substances produced in a given plant largely depends on the type of raw materials and fuel used. Sulfur dioxide $\left(\mathrm{SO}_{2}\right)$ is particularly harmful due to the formation of acid rain when reacting with air moisture, and thus, international regulations such as the Gothenburg Protocol [4] require emission ceilings of sulfur to be respected. To achieve these overall goals, national and international legislations apply emission limits for $\mathrm{SO}_{2}$ for various industries. Many desulfurization units are being designed to satisfy these requirements and remove $\mathrm{SO}_{2}$ efficiently.

In general, a desulfurization process may be categorized as wet, semidry (or spray-dry), or dry. The dominating flue gas desulfurization technology is absorption of $\mathrm{SO}_{2}$ in limestone slurry, known as wet scrubbing or wet flue gas desulfurization [5]. In a wet flue gas desulfurization process, the flue gas is passed through an aqueous solution containing aqueous sorbents, such as lime or seawater. The flue gas is cooled to its adiabatic saturation temperature which leads to a high $\mathrm{SO}_{2}$ conversion. In a dry flue gas desulfurization process, the dry sorbent is injected into the flue gas duct to get in contact with the flue gas, creating a solid by-product that accumulates with the fly ash. In a semidry flue gas desulfurization process, the sorbent is in an aqueous slurry. Semidry flue gas desulfurization is a well-established method for $\mathrm{SO}_{2}$ emission control. In the semidry process, a lime slurry is sprayed into a reactor where it comes in contact with hot flue gas. The water evaporates from the droplets, and the lime reacts with $\mathrm{SO}_{2}$ under both wet and dry conditions. As the by-product is a solid, the process provides a more manageable dry waste product. After the reactor, a cycle and/or a fabric filter or electrostatic 
precipitator for particulate control is present [6]. Wet, semidry, and dry flue gas desulfurization processes can reach efficiencies of up to 98,90 , and over $90 \%$, respectively [7].

In the cement industry, a particular variation of the semidry flue gas desulfurization process is employed, which is referred to as gas desulfurization absorber (GSA) [8]. The amount of water is controlled to keep the temperature above the adiabatic saturation temperature, producing a dry by-product. In contrast to conventional spray dryer absorber (SDA) systems, the GSA technology is well suited for retrofit application. Due to its small foot print, the GSA system can readily be retrofitted upstream of an existing electrostatic precipitator (ESP). The GSA has the advantage of being able to use the existing precipitator without any or small modifications, whereas SDA requires major rebuild and sometimes it is uneconomical [9].

To improve the performance of flue gas desulfurization plants and to optimize future plants, mathematical modeling of the absorption process is an important tool. In order to verify the model quality, lab scale and/or pilot-scale experiments are needed together with data from operation of the fullscale plants. Several mathematical models of the wet FGD process have been presented during the last decades. Olausson et al. [10] developed a model for removal of $\mathrm{SO}_{2}$ from the flue gas by absorption into lime slurry. The gas desulfurization unit that they considered had an absorption tower and an oxidation tank. Their model accounted for five important chemical reactions with a fixed rate. They validated their model with literature data, and satisfactory results were obtained. Gerbec et al. [11] developed nonstationary model of wet limestone desulfurization plant to study chemical and physical phenomena during operation. The absorption of $\mathrm{SO}_{2}$ from flue gas to counter current falling dispersed drops of liquid phase. Based on various boundary conditions and model input parameters (e.g., plant dimensions), dynamical responses to chosen parameters could be calculated by model and it could satisfactorily predict $\mathrm{SO}_{2}$, removal rate, chemical composition of the absorbing slurry, etc. It was verified on 3MW pilot plant at a coal fired power plant in Slovenia.

Gassner et al. [12] investigated the use of data-driven modeling techniques, in particular artificial neural networks, to analyze the operational behavior and performance of a flue gas desulfurization process. Kiil et al. [5] proposed a detailed model for a wet flue gas desulfurization pilot plant where all important ratedetermining steps, absorption of $\mathrm{SO}_{2}$, oxidation of $\mathrm{HSO}_{3}$, dissolution of limestone, and crystallization of gypsum were included.

In this study, the main focus has been to develop a sufficiently simple dynamic model that could represent a GSA process under normal operating conditions for a full-scale operational GSA. The kinetic model validation is performed using full-scale plant operational data. The simulation is utilized to study the process behavior; this includes the trend of the GSA process when undergoing changes in inlet conditions, such as temperature, flow rate, and $\mathrm{SO}_{2}$ concentration. The knowledge of the process behavior under dynamic condition is necessary to predict how the process will behave when implemented into different types of processing plants, where inlet conditions of the flue gas may differ and fluctuate. However, the previous works have not performed all the various analyses performed in this work on a full-scale operational GSA process.

The results obtained and the conclusions drawn in this study are beneficial, as various industrially known behaviors are included in the dynamic simulation, and these results can bring insight to further development of kinetic parameter estimation, control structure, and understanding of flue gas cleaning processes including desulfurization technologies. Therefore, the model can be used as a tool for design, optimization in technology, and for extrapolation of measured pilot plant data.

\section{Materials and Methods}

\subsection{Gas Suspension Absorber}

A schematic illustration of the GSA process is seen in Fig. 1. The main component of the process is the reactor where flue gas, with entrained fly ash and other solids flow into the reactor from the bottom through a flue duct system. From a nozzle lance, lime slurry consisting of hydrated lime and water, and additional water is sprayed upward by compressed air. The stream leaving the reactor contains the flue gas and the solid phase, which mainly consists of fly ash, un-reacted lime, and the by-products such as $\mathrm{CaSO}_{3} \cdot 0.5 \mathrm{H}_{2} \mathrm{O}$ and $\mathrm{CaSO}_{4} \cdot 0.5 \mathrm{H}_{2} \mathrm{O}$. The by-product formation is based on the following reactions:

$$
\begin{aligned}
& \mathrm{SO}_{2}+\mathrm{Ca}(\mathrm{OH})_{2} \rightarrow \mathrm{CaSO}_{3} \cdot 0.5 \mathrm{H}_{2} \mathrm{O}+0.5 \mathrm{H}_{2} \mathrm{O} \\
& \mathrm{CaSO}_{3} \cdot 0.5 \mathrm{H}_{2} \mathrm{O}+0.5 \mathrm{O}_{2} \rightarrow \mathrm{CaSO}_{4} \cdot 0.5 \mathrm{H}_{2} \mathrm{O}
\end{aligned}
$$

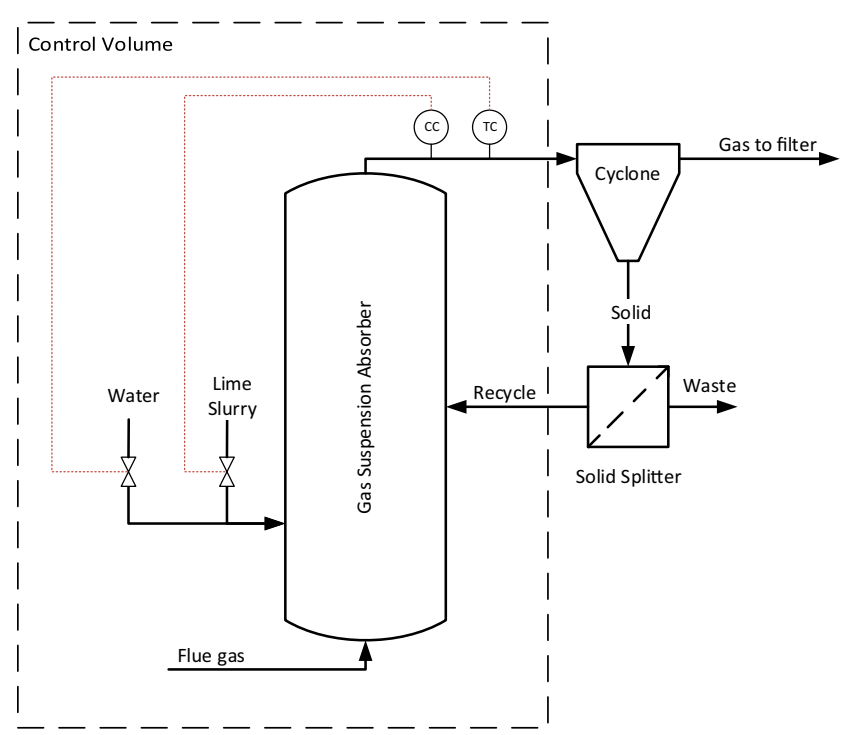

Fig. 1 GSA Process Flowsheet (model control volume emphasizednote that $\mathrm{CC}$ and TC are concentration control and temperature control) 
The solid phase is primarily separated from the flue gas in the cyclone. The separated solid phase is collected in the recirculation box where it is partly recycled into the reactor for maximizing efficiency. The gas from the cyclone flows into a filter, which is either an electrostatic precipitator or fabric filter, to precipitate solids, which were not separated in the cyclone. At this point, the flue gas exits the process and may be exhausted or continue to further cleaning.

The GSA process is controlled to maintain the required $\mathrm{SO}_{2}$ efficiency by keeping the temperature close to the adiabatic saturation temperature of the flue gas within a safety margin. This ensures maximum efficiency, minimal cost, and safety. To this end, control structure with two different control loops is considered. The first loop controls the outlet flue gas temperature by manipulating the amount of water injected into the reactor. The sensor is placed between the cyclone and the dust filter, and the offset in temperature is adjusted by changing the speed of the water pump. This cools the flue gas to the desired temperature and keeps a safety margin to the dew point which minimizes the usage of lime. The second loop manipulates the amount of lime slurry feed to the reactor to control the outlet concentration of $\mathrm{SO}_{2}$. An acid gas sensor is present in the reactor inlet as well as a sensor placed in the stack or silo, and from the deviation from the desired set point, the speed of the lime slurry pump is adjusted.

\subsection{Desulfurization Efficiency}

For the construction of a simulation model that is able to describe the GSA process dynamically, it is important to have a thorough understanding of the conditions present under normal operation. This information is important when constructing and validating the model, as they give expectations to the behavior of certain variables in the process.

The separation of $\mathrm{SO}_{2}$ from the flue gas occurs when the $\mathrm{SO}_{2}$ dissolves into the water and then reacts with the hydrated lime producing mainly calcium sulfite. The production of calcium sulfite occurs at a highly reduced rate in the absence of water. It is therefore important that a sufficient amount of water is present in the reactor for the dissolution of $\mathrm{SO}_{2}$. A high water to lime slurry injection ratio means a better coating for the flue gas particles. However, as explained by other researchers, it also produces a more dilute lime slurry, and therefore, more heat is required for drying the calcium salts $[9,13]$.

The high rate of recirculation in the process contributes to an increase in efficiency. Jozewicz and Rochelle [14] describe that the high rate of recirculation of hydrated lime provides higher $\mathrm{SO}_{2}$ conversion. Furthermore, high recirculation also increases conversion of silica and alumina if they are present in the flue gas. These react with the hydrated lime to form calcium aluminum silicate hydrates, which are more reactive in converting $\mathrm{SO}_{2}$ than the lime itself.
According to Liu and Shih [15], the presence of $\mathrm{CO}_{2}, \mathrm{O}_{2}$, and $\mathrm{NO}_{\mathrm{x}}$ with $\mathrm{SO}_{2}$ enhances semidry desulfurization. The temperature and the relative humidity also affect the desulfurization efficiency, and competitive carbonation reaction is moderately present according to Izquierdo and co-workers [16] and Ruiz-Alsop and Rochelle [17].

When the flue gas temperature is reduced, approaching its adiabatic saturation temperature, the absorption efficiency will increase. Due to safety and regulatory constraints, it is preferred to keep a distance from the adiabatic saturation temperature to avoid complications and to assure that the products are in a solid phase (that is all the water is evaporated) when leaving the reactor. This is termed as approach to adiabatic saturation temperature. According to Zhao et al. [18], the optimum temperature difference is $10{ }^{\circ} \mathrm{C}$ between gas and its corresponding saturation temperature. Thus, it is clear that the temperature has a significant impact on the $\mathrm{SO}_{2}$ conversion. Lowering the temperature increases conversion; however, this is not what a reaction rate consisting solely of the Arrhenius equation would predict. Thus, there is a need for a new reaction rate expression to represent the kinetic behavior [19].

\subsection{Reaction Kinetics}

Many researchers [16, 17, 20-22] have studied the kinetics of desulfurization. A vast selection of empirical reaction rate expressions for desulfurization reaction is proposed. However, the proposed empirical expressions differ from each other depending on process or experimental conditions and compounds present in the flue gas. Some of these expressions and the process conditions in which they were constructed are discussed here. Rahimi et al. [22] described the reaction rate expression as

$r_{\mathrm{SO}_{2}}=(0.4+0.0064 R H) y_{\mathrm{SO}_{2}}$

where $y_{\mathrm{SO}_{2}}$ is the gas phase molar fraction of $\mathrm{SO}_{2}$ and $\mathrm{RH}$ is the relative humidity in the reactor. This is a reaction rate expression for surface reactions. Thus, the surface area of the bed particles must be determined. The empirical reaction rate was defined through data gathered from a powder particle spouted bed, which is similar to the GSA process. However, the lime slurry is fed from the top of the reactor. Their studied process operates at $188^{\circ} \mathrm{C}$. The reaction rate depends on the relative humidity, $\mathrm{RH}$, and the mole fraction of $\mathrm{SO}_{2}, y_{\mathrm{SO}_{2}}$.

In Izquierdo et al. [16], a reaction was undergone in a fixed bed reactor and temperatures between 56.5 and $86.2^{\circ} \mathrm{C}$ with relative humidity ranging from 39.9 to $47.3 \%$. In their work, they concluded that the reaction rate does not experience any influence from $\mathrm{SO}_{2}$ concentrations, only temperature and relative humidity affect the reaction rate. Thus, an empirical zero-order reaction rate equation was proposed as follows:

$r_{\mathrm{SO}_{2}}=k(R H)^{z}$ 
where $z$ is the fitting parameter. The activation energy was fitted to a value of $32 \mathrm{~kJ} /$ mole. Irabien et al. [20] proposed an empirical model of the reaction rate. The empirical model parameters were fitted through lab-scale experiment. The experimental conditions were $62-72{ }^{\circ} \mathrm{C}$ with a relative humidity from 36 to $56 \%$. The empirical model of the reaction rate is expressed as

$r_{\mathrm{SO}_{2}}=\varepsilon k C_{\mathrm{SO}_{2}} \frac{R T}{\mu \exp (\theta / R H)}$

$$
\cdot\left[\exp \left(-\frac{\mu \exp (1 / R H)}{R T}\right) X_{S}-\exp \left(-\frac{\mu \exp (1 / R H)}{R T}\right) X_{m}\right]
$$

where $\varepsilon$ is the void space of the fluidized bed, $k$ is the rate constant, $R$ is the gas constant, $\mu$ and $\theta$ are fitting parameters, $X_{S}$ is the actual conversion, and $X_{m}$ is the maximum conversion. It is evident that the reaction rate is largely dependent on process conditions such as relative humidity and temperature. From Irabien et al. [20], the reaction was empirically defined as firstorder reaction. Under similar conditions, Izquierdo et al. [16] registered a reaction order of zero. $\mathrm{Li}$ and Keener [21] reported that in a high temperature process in a dry flue gas desulfurization process, the reaction order was dependent on the relative humidity and found to be 0.76 in the absence of humidity and of order 1 in the presence of humidity. At high $\mathrm{SO}_{2}$ concentrations, above $0.25 \%$ by volume, the reaction order approached zero.

Based on the kinetic studies and the description of the GSA process, it is evident that a number of physical parameters and process conditions influence the system behavior and need to be fitted to operational data. Furthermore, it is known that the relative humidity influences the reaction rate and so does the temperature. The temperature is affecting the rate expression through the Arrhenius expression and through the approach to adiabatic saturation temperature. Therefore, it is necessary to construct a kinetic rate expression which can be used in a model to simulate the GSA process under dynamic operation.

\subsection{Mathematical Modeling}

In order to build a dynamic model that can represent the GSA, the following assumptions have been made:

- Only the reaction for the production of calcium sulfite hemihydrate $\left(\mathrm{CaSO}_{3} \cdot 0.5 \mathrm{H}_{2} \mathrm{O}\right)$ is considered.

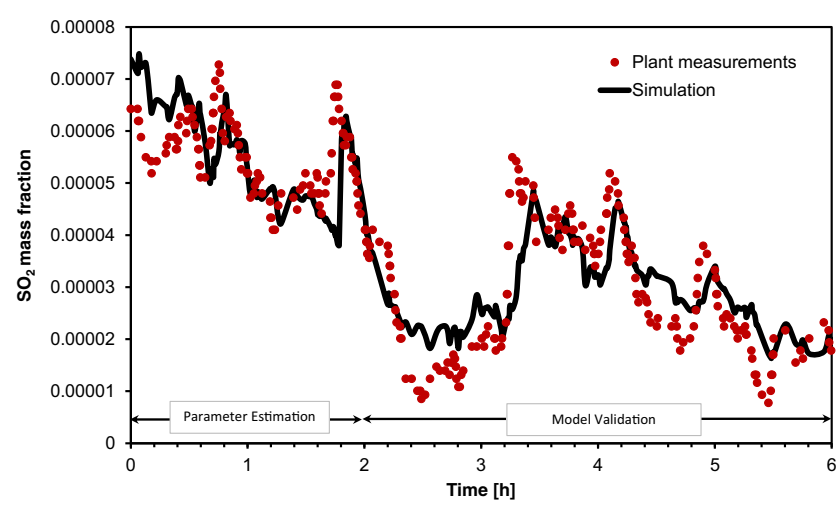

Fig. 2 Model validation of the kinetic model with operational data by Norcem A/S

- The reaction only occurs at the solid surface, and its reaction rate limited.

- The reactor is operated at atmospheric pressure.

- The mass of the solid phase material in the reactor is assumed constant.

- The gas phase is assumed to follow the ideal gas law and the molar mass of the flue gas is constant.

- Heat of reaction and mixing is neglected, and enthalpy of evaporation is assumed constant for all temperatures under normal operating conditions.

These assumptions are regarded as reasonable based on the previous works from the literature $[23,24]$ for the construction of a first principle simulation model. Effective mixing is caused by the fluidized bed where all reactions occur and the latent heat of vaporization dominates the energy balance. Based on the assumptions and employing mass and energy conservation laws, the reactor model is derived.

Prior to the derivation of the solid mass balance, the different streams need to be defined in the process through a simplified representation of the process that is given in Fig. 1. Note that the flowsheet given in the Fig. 1 represents the system boundaries as well.

\subsubsection{Mass Balance}

The volumetric flow rate of solid phase fed back into the reactor is defined by the following expression:

$v_{R}=v_{S P} \alpha \beta$

Table 1 Operating conditions utilized as model input

\begin{tabular}{|c|c|c|c|c|c|c|}
\hline & $\begin{array}{l}\text { Inlet gas flow } \\
\text { rate }(\mathrm{kg} / \mathrm{h})\end{array}$ & $\begin{array}{l}\text { Inlet } \mathrm{SO}_{2} \\
\text { concentration }(w / w)\end{array}$ & $\begin{array}{l}\text { Inlet gas } \\
\text { temperature (K) }\end{array}$ & $\begin{array}{l}\text { Inlet lime } \\
\text { slurry rate }(\mathrm{kg} / \mathrm{h})\end{array}$ & $\begin{array}{l}\text { Inlet water } \\
\text { rate }(\mathrm{kg} / \mathrm{h})\end{array}$ & $\begin{array}{l}\text { Reactor relative } \\
\text { humidity }(\%)\end{array}$ \\
\hline Min & $1.9090 \mathrm{E} 5$ & $4.0421 \mathrm{E}-4$ & 439 & 607 & 6082 & $17 \%$ \\
\hline Max & $1.9987 \mathrm{E} 5$ & $5.3756 \mathrm{E}-4$ & 441 & 856 & 6752 & $22 \%$ \\
\hline
\end{tabular}




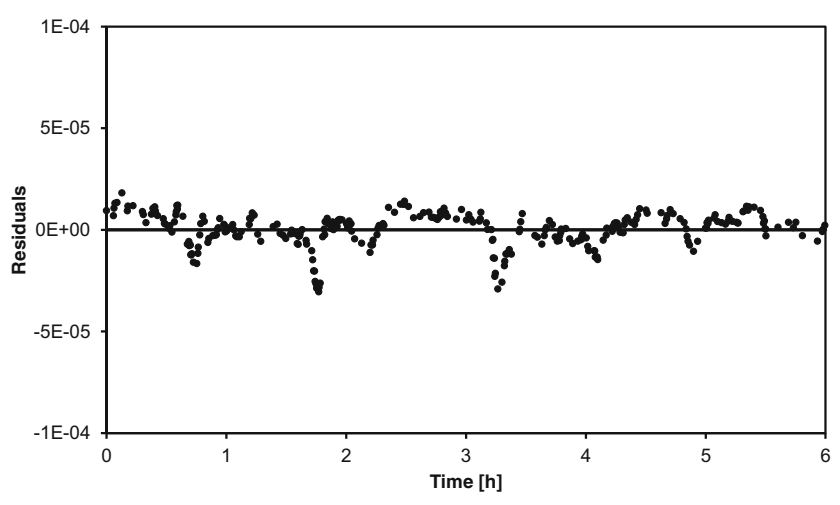

Fig. 3 Objective function residuals of the parameter estimation

where $\alpha$ is the recovery factor and $\beta$ is the fraction of material sent to the recirculation box which gets recycled to the reactor. The boundary for the dynamic model is the reactor (see dotted area in Fig. 1), but static models for the cyclone and the recirculation box are parts of the model for the overall process. The mass balances will consist of one total material balance for the solid phase and one balance for $\mathrm{SO}_{2}$. The water injected into the reactor from the water or the slurry pump is completely evaporated and assumed not to affect the mass balances significantly. Therefore, the total mass balance for the solid phase, $m_{S B}$ can be given as follows:

$\frac{d m_{S P}}{d t}=v_{F i} w_{S o l i d s, \text { in }}+v_{L S} w_{\text {Lime }, \text { in }}+v_{S P} \rho_{S P}(\alpha \beta-1)+r_{S O_{2}} V_{S P}$

The $\mathrm{SO}_{2}$ mass balance is

$\frac{d w_{\mathrm{SO}_{2}}}{d t}=\left(v_{\mathrm{F}}\left(w_{\mathrm{SO}_{2}, \mathrm{in}}-w_{\mathrm{SO}_{2}}\right)-r_{\mathrm{SO}_{2}} V_{\mathrm{SP}}\right) / m_{\mathrm{SO}_{2}}$

\subsubsection{Energy Balance}

To describe the variations in the reactor temperature, $T$, an energy balance is constructed. It is assumed that the reactor temperature is equal to the flue gas temperature. As the outlet flue gas temperature is an independent variable, the balance is constructed with respect to the flue gas temperature and is given as follows:

$$
\begin{aligned}
& \left(m_{F} c_{P, F}+m_{S P} c_{P, S P}\right) \frac{d T}{d t} \\
& \quad=v_{F} \rho_{F i} c_{P, F}\left(T_{F i}-T\right)-\left[v_{W}+v_{L S}\left(1-w_{\text {Lime }, i}\right)\right] \rho_{W} \Delta H_{W}^{v a p}
\end{aligned}
$$

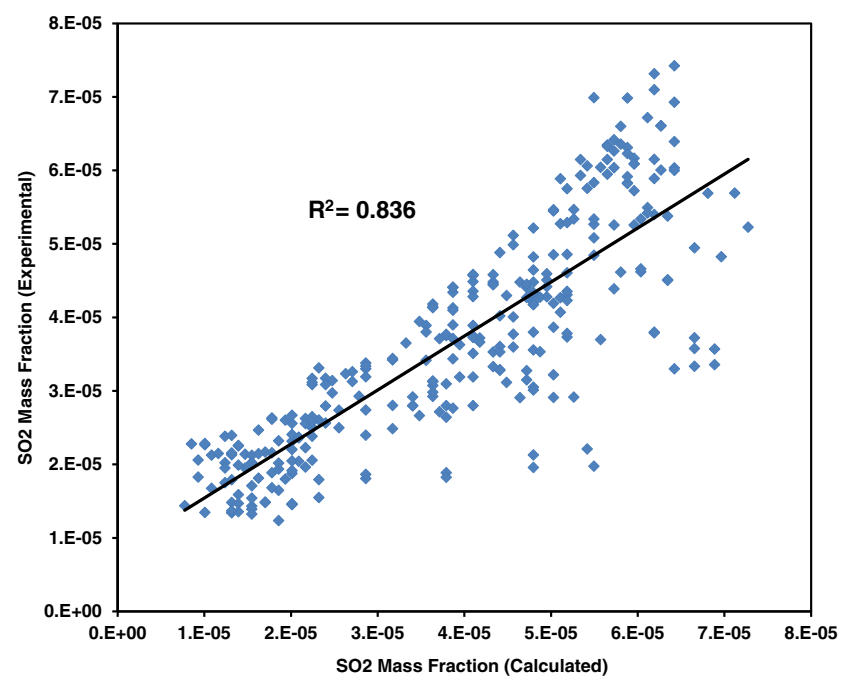

Fig. 4 Parity plot of the plant data versus model results

\subsubsection{Kinetic Modeling}

As the limitations of the existing reaction kinetics were discussed in Sect. 2.2, a more representative empirical reaction rate expression is needed to exhibit the kinetics of the GSA process. As there are many factors involved, the reaction will be defined to be of $n$th order. For the purpose of simplicity and considering the limiting possibility of the control system to measure the concentrations of all components of the flue gas, it is assumed that the reaction rate only depends on temperature, $\mathrm{SO}_{2}$ concentration, and on humidity. Irabien et al. [20] provided an expression to express the effect of the relative humidity on the reaction rate as follows:

$r_{\mathrm{SO}_{2}} \propto 1 /(\mu \exp (\theta / R H))$

where $\mu$ and $\theta$ are fitting parameters. It is known that when the temperature approaches the saturation temperature of the flue gas, the conversion approaches $100 \%[16,21,22,25]$. Thus, the reaction rate must obtain very high values. Otherwise, further apart from the adiabatic saturation temperature, the reactor temperature is the conversion will be lower yet will not approach zero, as the reaction rate expression value will increase as the Arrhenius term increases. To express this behavior, the following expression is proposed:

$r_{\mathrm{SO}_{2}} \propto 1 /\left(\gamma\left(T_{A S T}-T\right) R\right)^{2}$
Table 2 Estimated parameter values and $95 \%$ confidence interval

\begin{tabular}{llllll}
\hline Parameter & Lower bound & Upper bound & Initial Value & Final Value & $95 \% \mathrm{CI}$ \\
\hline$\Psi$ & 0 & $1 \mathrm{E} 20$ & $2.15 \mathrm{E} 15$ & $3.00 \mathrm{E} 15$ & - \\
$E$ & 0 & $1 \mathrm{E} 10$ & 36,000 & 32,744 & \pm 2285 \\
$N$ & 0 & 3 & 0.20 & 0.33 & \pm 0.07 \\
$\Theta$ & 0 & 100 & 3.33 & 14.01 & \pm 5.82 \\
\hline
\end{tabular}


Table 3 Cross-correlation matrix

\begin{tabular}{lllll}
\hline Parameter & $\Psi$ & $E$ & $n$ & $\theta$ \\
\hline$\Psi$ & 1 & - & - & - \\
$E$ & 0.979 & 1 & - & - \\
$n$ & -0.366 & -0.543 & 1 & - \\
$\theta$ & 0.480 & 0.302 & 0.529 & 1 \\
\hline
\end{tabular}

where $T_{A S T}$ is the adiabatic saturation temperature of the flue gas. $R\left(\mathrm{~J} \mathrm{~mol}^{-1} \mathrm{~K}^{-1}\right)$ is the gas constant and $\gamma\left(\right.$ mole $\left.\mathrm{J}^{-1}\right)$ is a fitting parameter; both are added to satisfy the units. The empirical reaction rate is therefore be expressed as

$r_{\mathrm{SO}_{2}}=k_{0} \frac{\exp \left(-E_{a} /(R T)\right)}{\gamma^{2} \mu R^{2}\left(T_{A S T}-T\right)^{2} \exp (\theta / R H)} w_{S_{2}}^{n}$

$k_{0}, \mu$, and $\gamma$ will be collected into a new parameter that is defined as $\psi\left(\mathrm{J}^{2}\right.$ mole $\left.\mathrm{e}^{-2} \mathrm{~h}^{-1}\right)$. Therefore, Eq. (12) is a new empirical reaction rate model proposed in this work and is expressed as follows:

$r_{\mathrm{SO}_{2}}=\psi \frac{\exp \left(-E_{a} /(R T)\right)}{R^{2}\left(T_{A S T}-T\right)^{2} \exp (\theta / R H)} w_{S O_{2}}^{n}$

The parameter, $\psi$, will serve as the pre-exponential factor. $\theta$ will determine the degree of the effect that relative humidity has on the reaction rate. The reaction order, $n$, will influence the effect from the $\mathrm{SO}_{2}$ concentration on the reaction rate. Thus, the fitting parameters can represent the dependence on temperature, $\mathrm{SO}_{2}$ concentrations, and humidity.

The fitting parameters are assigned reasonable initial values in the course of simulations to provide a realistic conversion. The initial value will be derived from previously fitted parameters by Irabien et al. [20], Izquierdo et al. [16], and $\mathrm{Li}$ et al. [21]. However, as the process conditions differ, the parameters must be refitted to operational data.

\subsection{Parameter Estimation}

The total number of data points is 360 data points with a data resolution of $1 \mathrm{~min}$. For parameter fitting, a period of $2 \mathrm{~h}$ (120 data points) was used from a full-scale operational data set provided by Norcem A/S (6 h in total-360 data points). The following objective function, $F_{o b j}$, was defined in which
$\bar{Y}_{\mathrm{SO}_{2}}$ is the mean $\mathrm{SO}_{2}$ output concentration and $\tilde{Y}_{\mathrm{SO}_{2}}$ is measured $\mathrm{SO}_{2}$ output. The fitted parameters, $\operatorname{Par}\{\psi, E, n, \theta\}$, are given in Table 2.

$$
\begin{aligned}
& \text { Par }=\arg \min _{P a r} F_{o b j} \\
& F_{o b j}=\sum_{j=1}^{N} \sum_{i=1}^{M}\left(\frac{Y_{S_{2}, i j}-\tilde{Y}_{S_{2}, i j}}{\bar{Y}_{S O_{2}, i j}}\right)^{2}
\end{aligned}
$$

The optimization has been performed using the LevenbergMarquardt method [26].

\section{Results and Discussion}

\subsection{Model Validation}

In this step, the parameter fitting, model validation, and process behavior are investigated. This is based on operational data, in which the measured variables utilized were inlet gas flow rate $\left(v_{F}\right)$, inlet $\mathrm{SO}_{2}$ concentration $\left(w_{S O 2 i}\right)$, inlet gas temperature $\left(T_{F i}\right)$, inlet lime slurry rate $\left(v_{L S}\right)$, inlet water rate $\left(v_{w}\right)$, and reactor relative humidity $(R H)$ which is a product of hard measurement in the plant. Although it may seem to be a problematic parameter, it is necessary to be considered, according to Irabien et al. [20], since it affects the reaction kinetics and is therefore included in the kinetic model. Note, however, that the plant measurements may contain some degree of uncertainty and/or noise which authors did not have any control on them. Therefore, a simple uncertainty propagation can be performed to have an order of magnitude of the model uncertainty similar to the work of Neveux and Le Moullec [27]. However, this analysis is not carried out in this work. A summary of the operation data with their respective minimum and maximum value is given in Table 1.

These measured variables will be utilized as inputs to the model and the output $\mathrm{SO}_{2}$ concentration for validation. The model output after optimization of the parameters can be compared to the operational data in Fig. 2. It can be asserted that the model reproduces the plant data trend very well. However, due to the simplifications made in course of modeling and reaction rate manipulation, relative errors are observed. The values of the residuals are given in Fig. 3.

In order to further validate and quantitatively asses the goodness of the fit, confidence intervals (CI) were calculated
Table 4 Reduced model fitting parameters with confidence interval

\begin{tabular}{llllll}
\hline Parameter & Lower bound & Upper bound & Initial value & Final value & $95 \%$ CI \\
\hline$k^{*}$ & 0 & $1 \mathrm{E} 20$ & $2.15 \mathrm{E} 15$ & $4.18 \mathrm{E} 10$ & $\pm 1 \mathrm{E} 8$ \\
$n$ & 0 & 3 & 0.20 & 0.36 & \pm 0.04 \\
$\theta$ & 0 & 100 & 3.33 & 12.68 & \pm 6.15 \\
\hline
\end{tabular}


Fig. 5 Model validation of the reduced kinetic model with operational data by Norcem A/S

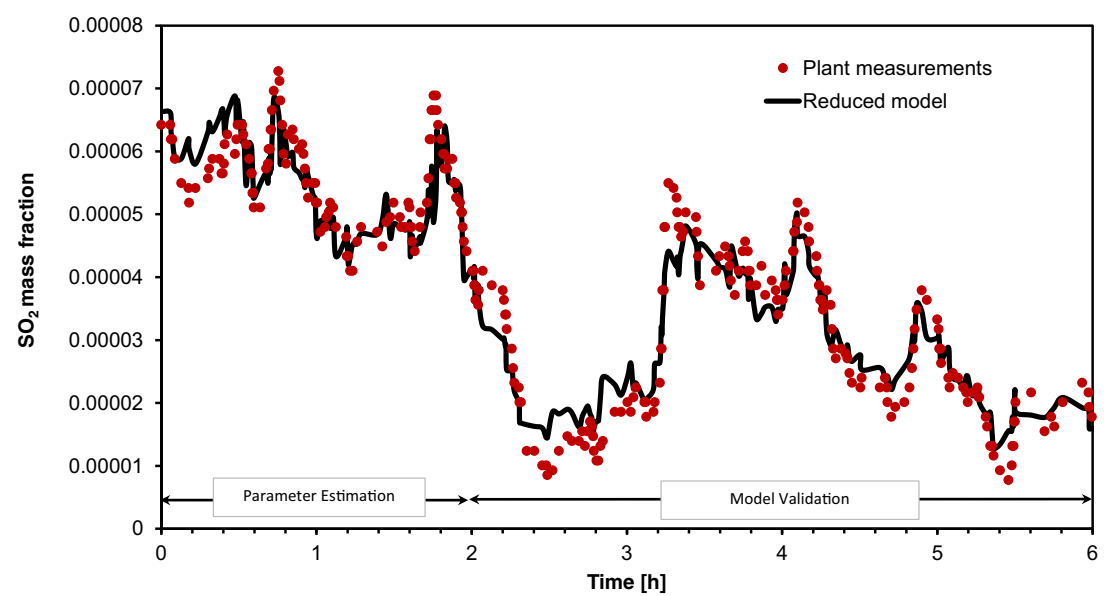

for the estimated parameters. The value of the estimated parameters and their corresponding $95 \%$ confidence interval is given in Table 2.

Note that the ability of the model to reproduce the data trend was expected, considering the number of model parameters and assumptions. The R-squared value and the trend of the calculated versus experimental data in the parity plot (Fig. 4) show that the model very well reproduces the trend of the dataset. However, the simplicity of the model with respect to the number of measurable variables provides a very good tool for analyzing plant dynamic behavior.

In order to further validate and quantitatively asses the goodness of the fit, confidence intervals $(\mathrm{CI})$ were calculated for the estimated parameters. The value of the estimated parameters and their corresponding $95 \%$ confidence interval is given in Table 2 .

Based on the confidence interval, the capability of the model to predict the behavior of a GSA process is satisfactory due to the mechanistic model and the range of conditions for which it was fitted.

To investigate the correlations between the different identified kinetic parameters, the cross-correlation matrix was evaluated based on the parameter fitting. In Table 3, the cross-correlation between the parameters is reported and based on this is evident that a sufficiently low correlation is observed and the estimates are reasonable. Between the parameters $\Psi$ and $E$, the highest correlation of roughly $98 \%$ is observed compared to the other pairs of parameters. This is expected, as $\Psi$ is a similar parameter as the pre-exponential factor in the Arrhenius equation and is known to correlate strongly with the activation energy. Note, however, for the comprehensive analysis of modeling results, that it is necessary to know how reliable the parameter estimates are. In practice insufficient or noisy data, as well as the strong parameter correlation or even their functional relation may prevent the unambiguous determination of parameter values; therefore, an identifiability analysis is suggested. However, in this work since the main focus has been given to model development, this analysis is not performed.
When the cross correlation between any two model parameters is less than -0.7 or greater than 0.7 , there is a strong collinearity in the "independent" variables selected. Looking at the values of the cross-correlation matrix for the pair of $\Psi$ and $E$, it is readily observed that the correlation coefficient between $\Psi$ and $E$ is 0.979 . These are essentially the same parameter. Therefore, one or the other needs to be removed and the analysis redone. The plant data that has been obtained shows that the temperature of the reactor outlet fluctuates between 345 and $355 \mathrm{~K}$. It is therefore possible to express the kinetic term of the Arrhenius expression through a temperature-independent reaction rate constant $k$ expression. Thus, the kinetic expression of Eq. 13 is modified to the following:

$r_{\mathrm{SO}_{2}}=k^{*} \frac{w_{\mathrm{SO}_{2}}^{n}}{R^{2}\left(T_{A S T}-T\right)^{2} \exp (\theta / R H)}$

The new parameter $k^{*}$ is the fixed reaction rate constant for the Arrhenius term at $350 \mathrm{~K}$. The model has therefore been reduced to three fitting parameters to avoid the high crosscorrelation between the pre-exponential factor and the activation energy. The model is refitted to the plant data in the same

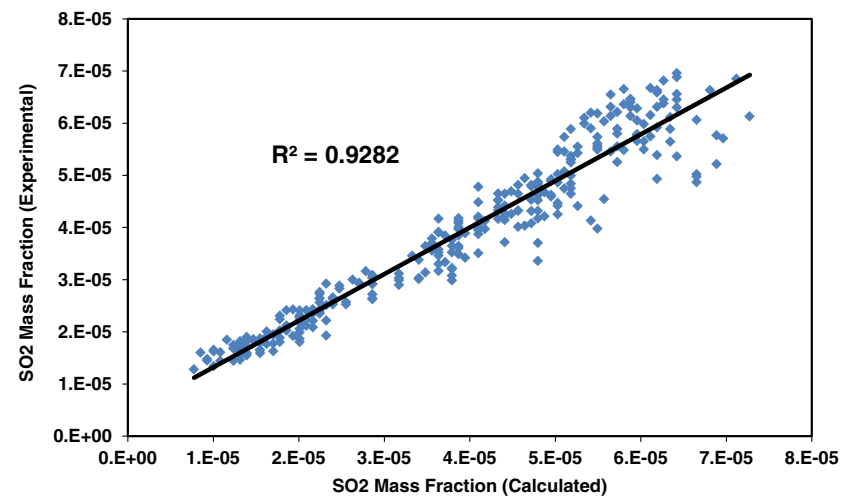

Fig. 6 Parity plot of the plant data versus reduced model results. Model is best recommended in the range $w_{\mathrm{SO} 2} \varepsilon$ [1.E-5-7.E-5] 
Fig. 7 Comparison with GSA reduced model with the model for semidry

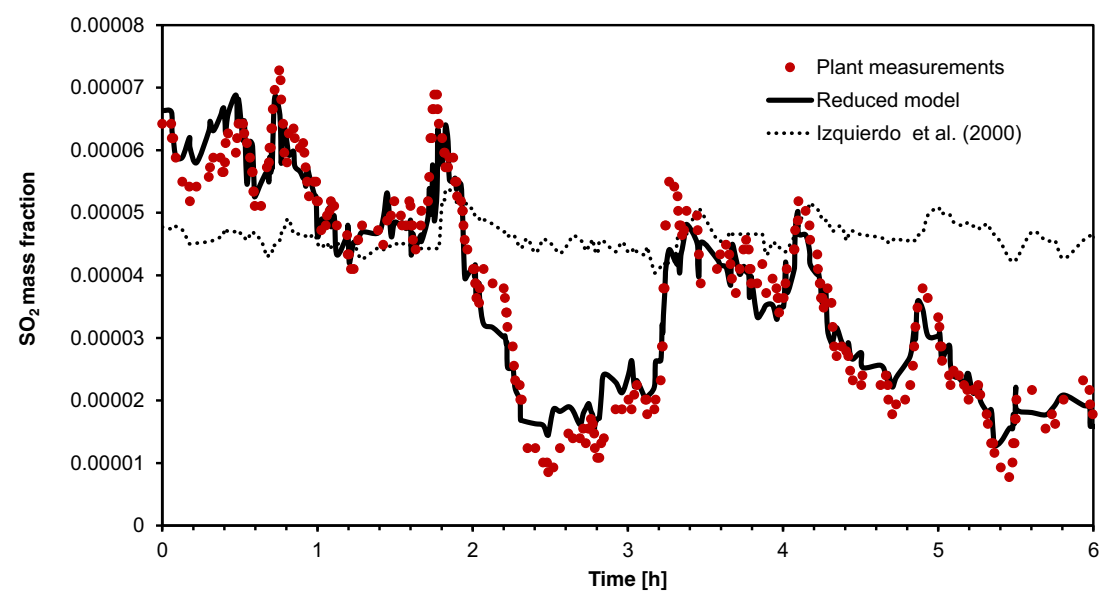

way the original model was fitted. In Table 4, the resulting values for the fitting parameters are given.

Figure 5 shows the performance of the reduced kinetic model with the parameters in Table 4 compared to plant measurements. It can be seen that model prediction has significantly improved; however, there are over and under predictions which may be due to the uncertainty in the plant measurements, and hence the applicability of the model prediction is predominantly recommended for the $\mathrm{SO}_{2}$ mass fraction in the range $w_{\mathrm{SO} 2} \varepsilon$ [1.E-5-7.E-5]. Note, however, that there is no systematic time lag in the model predictions and these observations are based on all of the system inputs and model predictions since the modeling here is based on first principles rather than a data-driven model. Figure 6 shows the R-squared value and the trend of the calculated versus experimental data in the parity plot (Fig. 6) which reveals the improved model prediction of experimental data by the reduced kinetic model.

The model presented in this paper has been shown to reliably be able to predict the $\mathrm{SO}_{2}$ concentration on the outlet of the GSA process. The model must also be compared to other similar models that are provided in literature to represent similar processes like the GSA. Izquierdo et al. [16] proposed a reaction kinetic model only dependent on the relative humidity and some fitting parameters as given in Eq. 4. This model is now compared with the reduced model presented in this work. The results are given in Fig. 7. As it can be seen, the model by Izquierdo et al.[8] lacks the ability to predict the process behavior of the GSA system.

It should however be noted that the model by Izquierdo et al. [16] was fitted on data from a fixedbed reactor. However, with the same reaction and similar operational conditions as with the current GSA process, note, however, that the comparison with other existing models, for example Rahimi et al. [22], was not performed since the operating window at which they fitted their parameters was out of the operating range considered in this work.

\subsection{Dynamic Analysis}

\subsubsection{Sensitivity Analysis}

In order to further understand the behavior of the kinetic model, a sensitivity analysis of $\mathrm{SO}_{2}$ conversion to the model parameters was performed.

The selected model parameters for this purpose were relative humidity $(\mathrm{RH})$ and inlet gas temperature. The results are shown in Fig. 8. It can be seen from Fig. 8a that as the relative humidity increases, $\mathrm{SO}_{2}$ conversion also increases. At RH less than $20 \%$, changes in relative humidity are more significant. Figure $8 \mathrm{~b}$ also shows
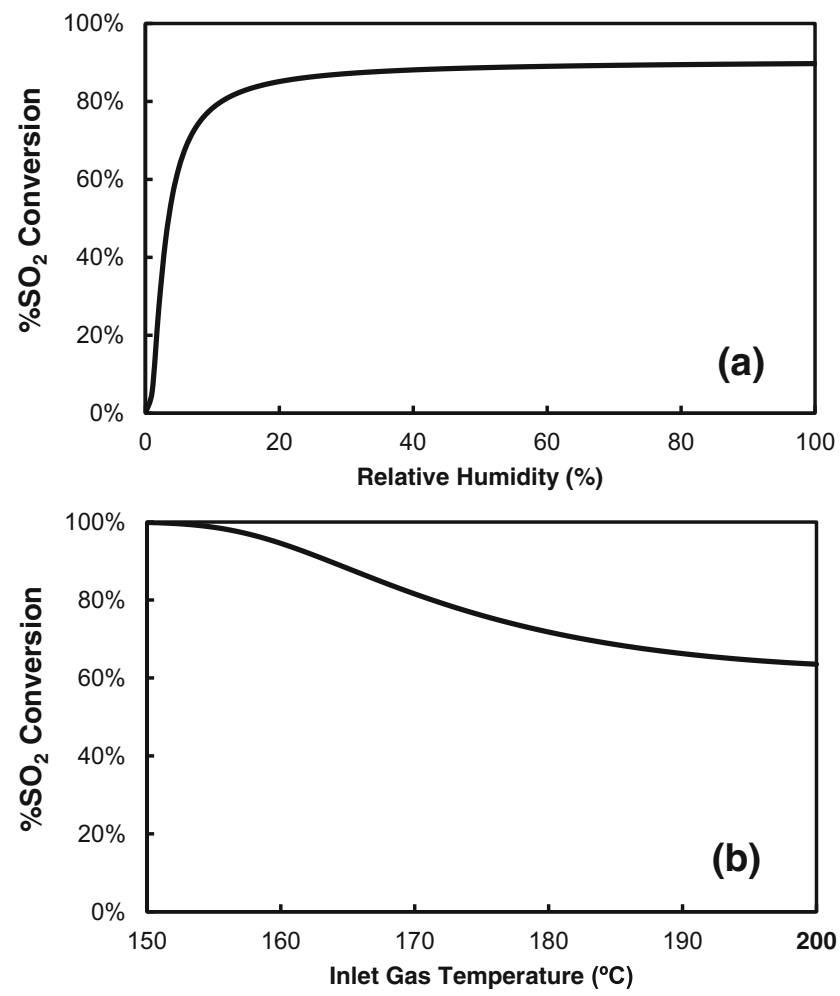

Fig. 8 The sensitivity of $\mathrm{SO}_{2}$ conversion to kinetic model parameters 
that there is a reciprocal relationship between $\mathrm{SO}_{2}$ and inlet gas temperature. The results in Fig. 8a, b are well matching with what has been found in previous studies (see Sect. 2.1). They confirm that relative humidity and inlet gas temperature are the process variables that affect the desulfurization efficiency.

\subsubsection{Open-Loop Analysis}

The process behavior under open-loop conditions will be presented by imposing different disturbance to inlet variables (temperature, $\mathrm{SO}_{2}$ concentration, and mass flow rate) once at the time. The disturbances were chosen to be $2 \%$ decrement and increment of the value of the inlet variables. The results are given in Fig. 9. The effect of inlet temperature on the $\mathrm{SO}_{2}$ conversion and outlet temperature over a time span of $2 \mathrm{~h}$ is seen in Fig. 9a. It can be seen that as the temperature increases, the conversion is decreased. Nonlinearity is observed as a reverse disturbance returns an opposite trend with less magnitude. The process has a higher sensitivity to a temperature disturbance compared to other disturbances. It should be noted that the $2 \%$ increment of the inlet temperature drives the temperature to reach the adiabatic saturation temperature; therefore, conversion approaches $100 \%$. A similar trend is observed in Fig. 9b, c where disturbance is in the form of a $2 \%$ increment or decrement in mass flow rate and $\mathrm{SO}_{2}$ concentration. However, in Fig. 9c, it can be seen that the change in $\mathrm{SO}_{2}$ concentration does not affect the outlet temperature and its effect on the $\mathrm{SO}_{2}$ conversion is little which can be due to the relatively small disturbance that was imposed. In other words, the inlet disturbance of $\mathrm{SO}_{2}$ concentration does not affect the energy balance since in the reaction rate, the
Fig. 9 Open-loop simulation of the model with parameters from Table 2 and given inlet disturbances
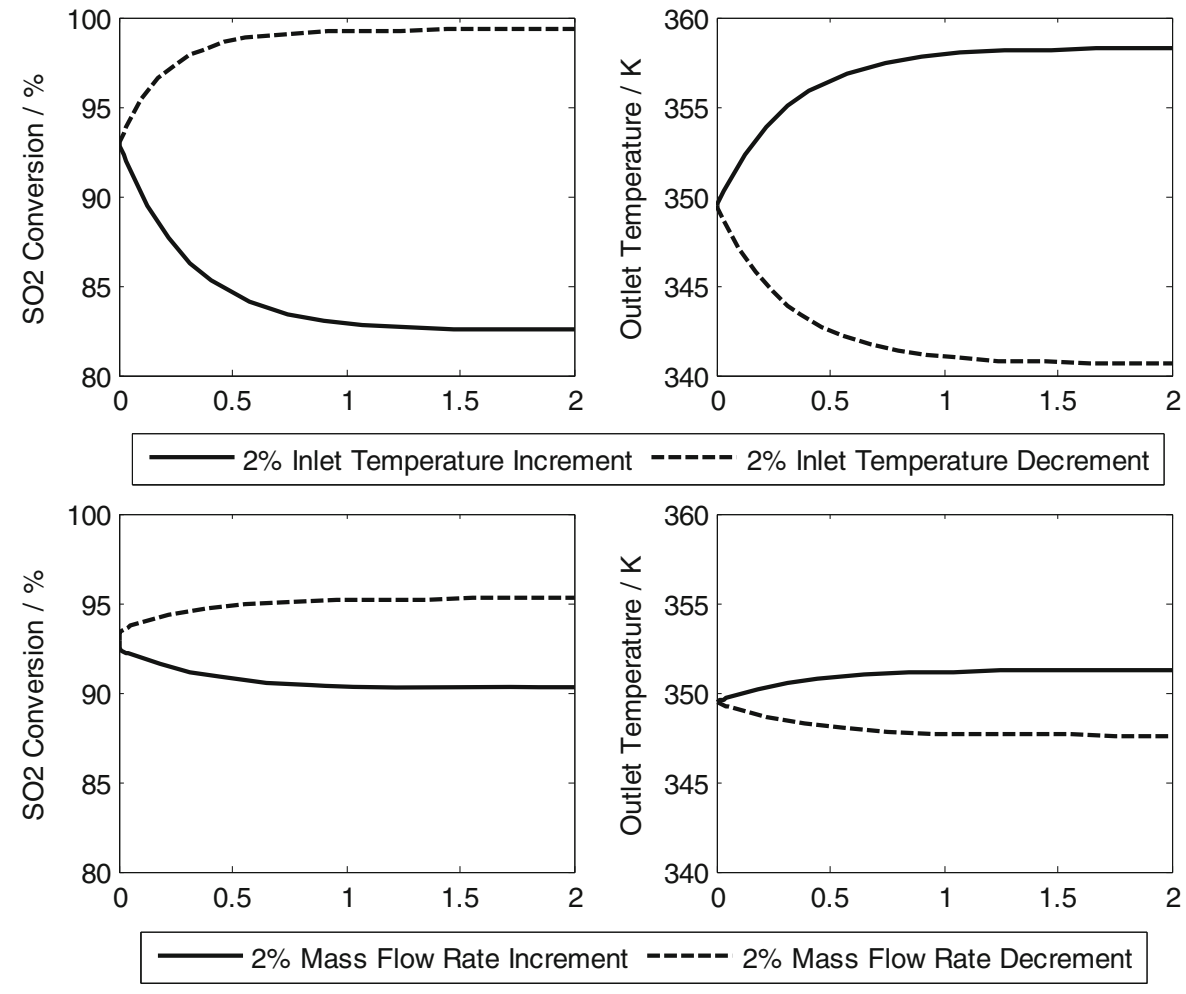

(b)
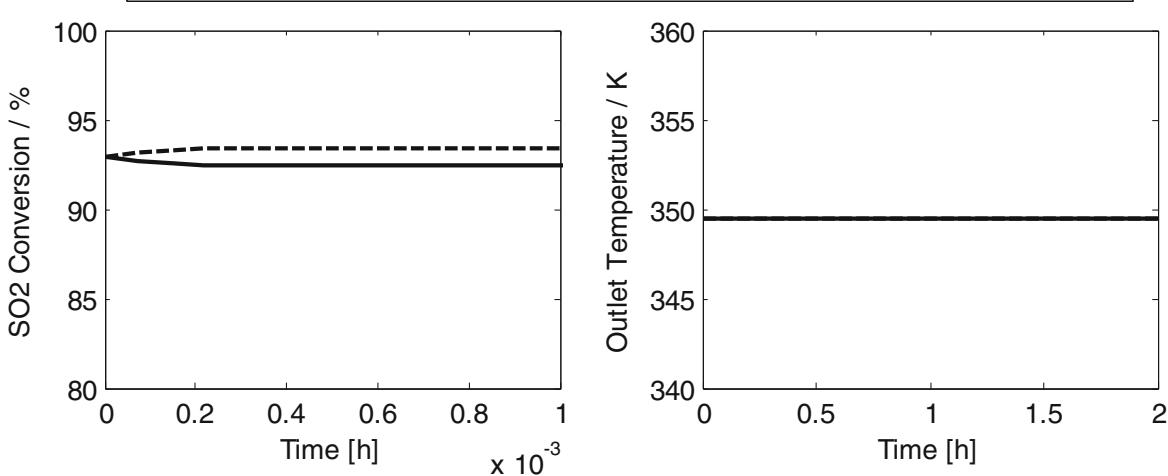

(c) 
Fig. 10 Closed loop simulation of the model with parameters from Table 2 with an inlet temperature disturbance of $1 \%$ increment
Fig. 11 Closed loop simulation of the model with parameters from Table 2 with an inlet flue gas mass flow rate disturbance of $1 \%$ increment
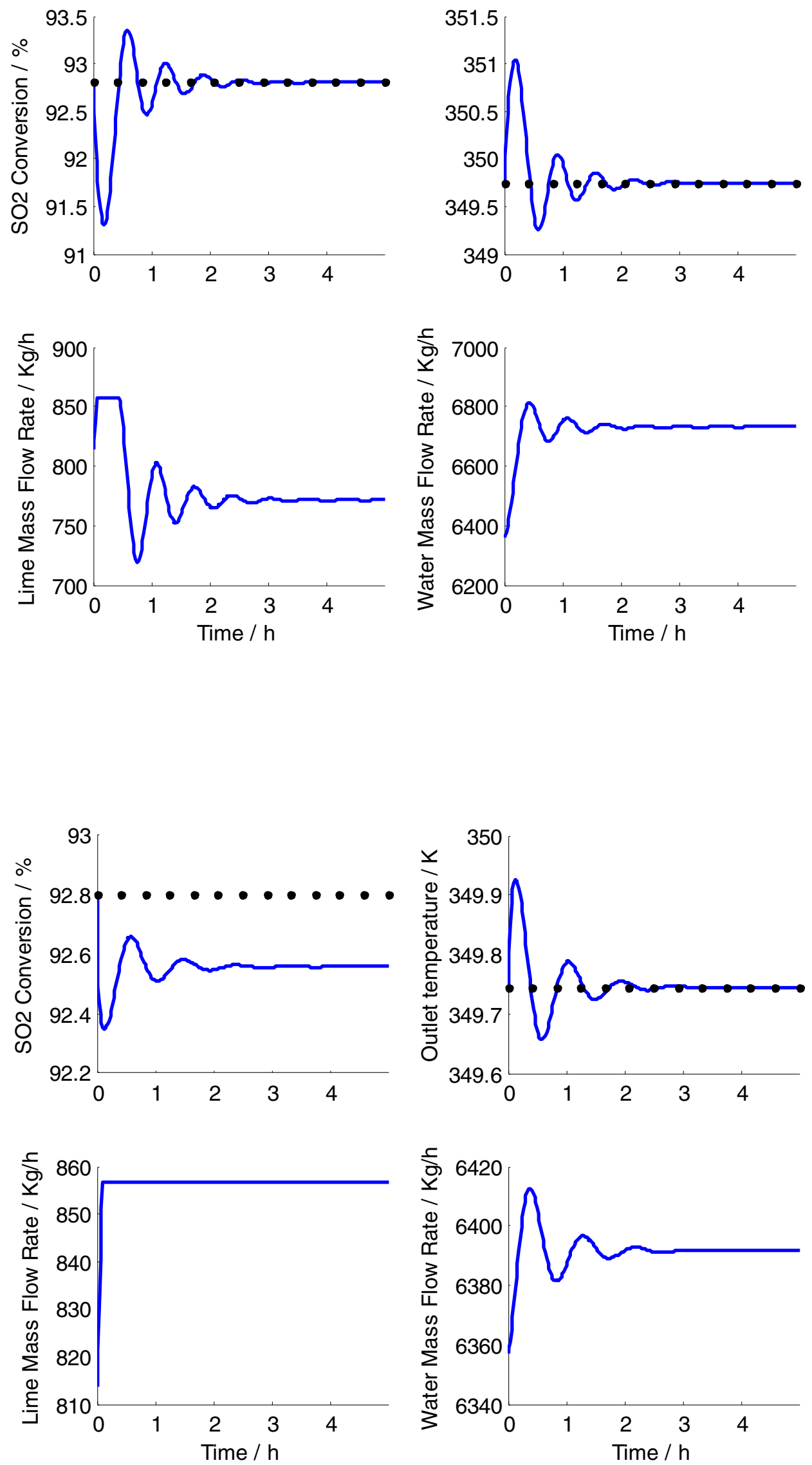
temperature dominates the effect of $\mathrm{SO}_{2}$ concentration. The open-loop analysis shows that the process behavior matches the expectations from the model construction, e.g., mass and energy balance and proposed reaction rate expression.

\subsubsection{Closed-Loop Analysis}

Three closed-loop simulations are run for three different step disturbances with both controllers active: inlet temperature in Fig. 10, inlet mass flow rate of flue gas in Fig. 11, and inlet $\mathrm{SO}_{2}$ fraction in Fig. 12. As it can be seen for a small temperature change, both controllers are active and both the set-points for the $\mathrm{SO}_{2}$ and outlet temperature are satisfied. However, this was obtained after approximately $3 \mathrm{~h}$ of regulating with significant oscillation. However, for the flow disturbance, the control law cannot satisfy the set-points, saturating the lime slurry flow at its maximum resulting in a too low $\mathrm{SO}_{2}$ conversion. When a disturbance is imposed for the inlet $\mathrm{SO}_{2}$ concentration, it could have been expected that the temperature should not have been affected as experienced in the open-loop simulation. However, the lime slurry is manipulated to improve the $\mathrm{SO}_{2}$ conversion, but this lowers the outlet temperature, which activates the water flow rate. For approximately two and a half hours, the two points are moving in opposite direction with the same slope, though the lime slurry contains a significant lower amount of water. The closed-loop simulations showed that the pump manipulation of slurry and water conflict with each other due to the similar task that they carry out in the process; however, this is also a well-known behavior which needs to be prevented by the plant operator.

\section{Conclusions}

A dynamic model was developed for the industrial gas suspension absorber. For the model, an empirical reaction rate expression was constructed and together with the model was validated to industrial scale plant data. The proposed reaction rate expression is able to take into account the effects of relative humidity, $\mathrm{SO}_{2}$ concentration, and distance to adiabatic saturation temperature together, which previously was not possible with existing models in literature. The model and its fitted parameters were shown to be able to predict process behavior under dynamic operating conditions however with a low accuracy. In order to improve the predictability of the model, a reduced form of it was presented based on the cross-correlation analysis. It was shown that the reduced model can very well predict the operational data behavior. Furthermore, the kinetic model was compared with an existing model in the literature, and it was shown that it can reproduce the plant data with high accuracy. In addition, process trends and effects of relative humidity and flue gas temperature on
Fig. 12 Closed loop simulation of the model with parameters from Table 2 with an inlet $\mathrm{SO}_{2}$ mass fraction disturbance of $0.1 \%$ increment
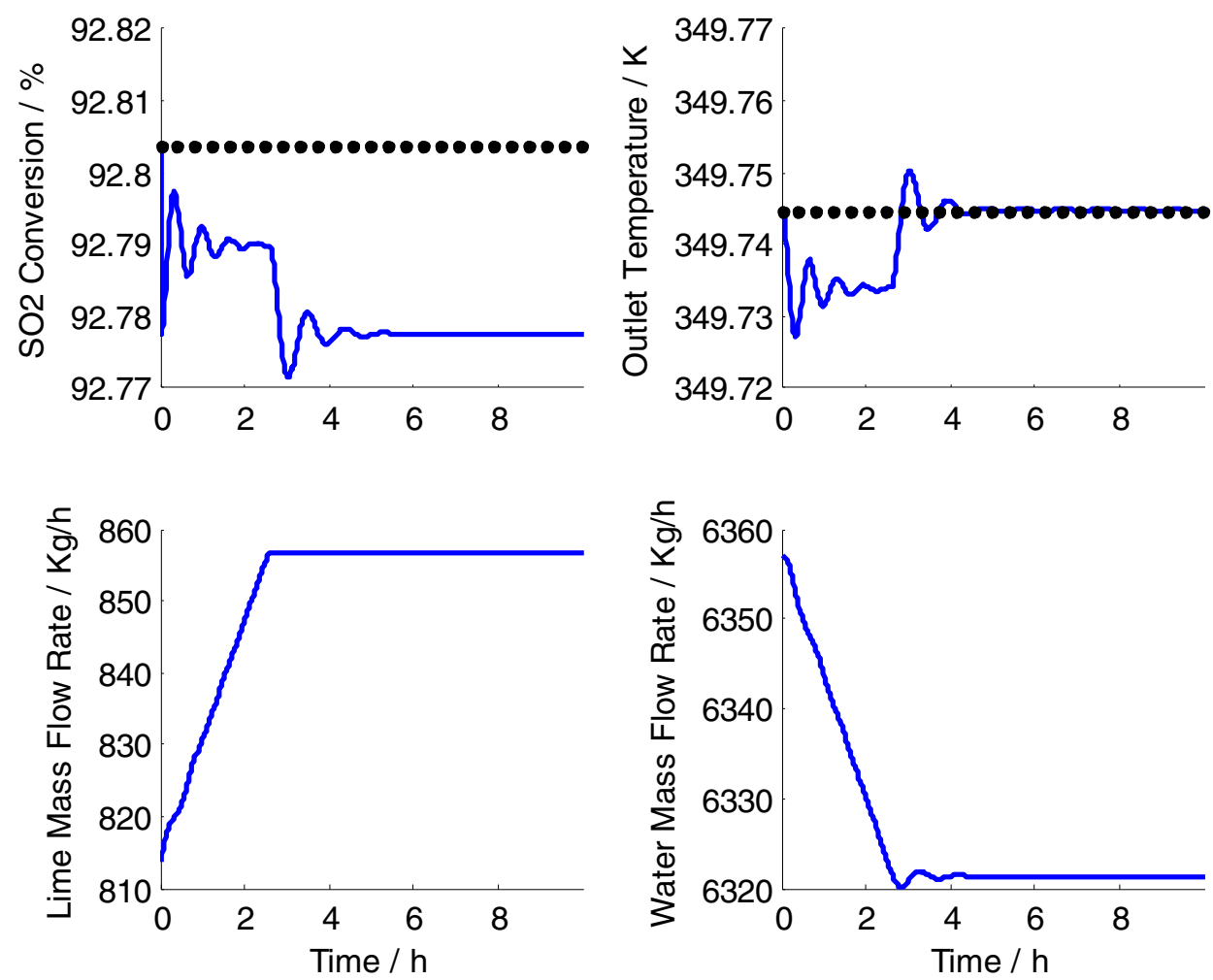
$\mathrm{SO}_{2}$ conversion were shown to be replicable through sensitivity study. Through dynamic study of open-loop and closed-loop simulation, the usefulness of the model were shown, and this includes the expected model behavior from literature and reflection of known operating issues from heuristics. The simple model has therefore proved useful for the analysis, simulation, and understanding of a gas suspension absorber and can further be utilized for study of the same or similar processes.

\section{Abbreviations}

\section{Symbol}

$\begin{array}{ll}c_{p, i} & \text { Specific heat capacity of species } i \\ E_{a} & \text { Activation energy } \\ F_{o b j} & \text { Objective function } \\ k & \text { Reaction rate constant } \\ k_{0} & \text { Pre-exponential factor } \\ m & \text { Mass } \\ n & \text { Reaction order } \\ R & \text { Gas constant } \\ r & \text { Reaction rate } \\ R H & \text { Relative humidity } \\ T & \text { Temperature } \\ V & \text { Volume } \\ v_{j} & \text { Volumetric flow rate of stream } i \\ w & \text { Mass fraction } \\ X_{m} & \text { Maximum conversion } \\ X_{S} & \text { Actual conversion } \\ Y & \text { Output (model) } \\ \tilde{Y} & \text { Output (data) } \\ \bar{Y} & \text { Mean output } \\ y_{i} & \text { Mole fraction of species } i \\ z & \text { Fitting parameter }\end{array}$

\section{Greek symbols}

$\begin{array}{ll}\alpha & \text { Separator solid/gas separation fraction } \\ \beta & \text { Recirculation fraction } \\ \gamma, \mu, \theta, \psi & \text { Fitting parameter } \\ \Delta H_{W}^{\text {vap }} & \text { Heat of evaporation of water } \\ \varepsilon & \text { Void space } \\ \rho & \text { Density }\end{array}$

\section{Subscripts}

$A S T$ Adiabatic saturation temperature

$F \quad$ Gas flow

$F_{i} \quad$ Inlet gas flow

LS Lime slurry

$\mathrm{SO}_{2} \quad$ Sulfur dioxide

Solid Solid particulates

SP Solid phase

$W \quad$ Water
Acknowledgments The authors wish to acknowledge the staff from FLSmidth and Norcem Brevik who have contributed to establishing the plant, the tests, and the data used in this article.

\section{References}

1. Farsi, A., Shadravan, V., Mansouri, S.S., et al.: A new reactor concept for combining oxidative coupling and steam re-forming of methane: modeling and analysis. Int. J. Energy Res. 37, 129-152 (2013). doi:10.1002/er.1881

2. Xu, Y., Carmichael, G.R.: An assessment of sulfur deposition pathways in Asia. Atmos. Environ. 33, 3473-3486 (1999). doi:10.1016/ S1352-2310(98)00356-2

3. Smith, S.J., Van Aardenne, J., Klimont, Z., et al.: Anthropogenic sulfur dioxide emissions: 1850-2005. Atmos. Chem. Phys. 11, 1101-1116 (2011). doi:10.5194/acp-11-1101-2011

4. Gothenburg Protocol: Protocol to the 1979 Convention on longrange transboundary air pollution to abate acidification, eutrophication and ground-level ozone. (1999)

5. Kiil, S., Michelsen, M.L., Dam-johansen, K.: Experimental investigation and modeling of a wet flue gas desulfurization pilot plant. Ind. Eng. Chem. Res. 37, 2792-2806 (1998). doi:10.1021/ ie9709446

6. Strömberg, A.-M., Karlsson, H.T.: Limestone based spray dry scrubbing of SO2. Chem. Eng. Sci. 43, 2095-2102 (1988). doi: 10.1016/0009-2509(88)87089-1

7. United States Environmental Protection Agency: Air Pollution Control Fact Sheet - Flue Gas Desulfurization (FGD) - Wet, Spray Dry, and Dry Scrubbers. (2003)

8. Jepsen, O.L., Paone, P.T., John, S., Dejoseph, D.: Method for eliminating spikes of mercury emissions. United States Patent Number: US20100300864A1 (2010)

9. Felsvang, K., Olsen, P.B., Jensen, F., et al.: The GSA dry scrubbing technology for retrofit applications. Environ. Prog. 18(2), 75-79 (1999). doi:10.1002/ep.670180210

10. Olausson, S., Wallin, M., Bjerle, I.: A model for the absorption of sulphur dioxide into a limestone slurry. Chem. Eng. J. 51, 99-108 (1993). doi:10.1016/0300-9467(93)80016-H

11. Gerbec, M., Stergaršek, A., Kocjančič, R.: Simulation model of wet flue gas desulphurization plant. Comput. Chem. Eng. 19, 283-286 (1995). doi:10.1016/0098-1354(95)87050-4

12. Gassner, M., Nilsson, J., Nilsson, E., et al.: A data-driven approach for analysing the operational behaviour and performance of an industrial flue gas desulphurisation process. In: Computer Aided Chemical Engineering. Elsevier, pp 661-666 (2014)

13. Miller, S.W., Jensen, F., Nielsen, K.E.: The gas suspension absorber at Norcem's Brevik plant. In: IEEE Cement Industry Technical Conference (Paper). (2011)

14. Jozewicz, W., Rochelle, G.T.: Fly ash recycle in dry scrubbing. Environ. Prog. 5, 219-224 (1986). doi:10.1002/ep.670050405

15. Liu, C.F., Shih, S.M.: Effects of flue gas components on the reaction of $\mathrm{Ca}(\mathrm{OH}) 2$ with so2. Ind. Eng. Chem. Res. 45, 8765-8769 (2006). doi:10.1021/ie0605534

16. Izquierdo, J.F., Fité, C., Cunill, F., et al.: Kinetic study of the reaction between sulfur dioxide and calcium hydroxide at low temperature in a fixed-bed reactor. J. Hazard. Mater. 76, 113-123 (2000). doi:10.1016/S0304-3894(00)00187-4

17. Ruiz-Alsop, R., Rochelle, G.T.: Effect of Relative Humidity and Additives on the Reaction of Sulfur Dioxide with Calcium Hydroxide. EPA/600/2-88/037. (1988)

18. Zhao, X.D., Ma, C.Y., Dong, Y., Wu, S.H.: Development and application of double circulating fluidized bed-flue gas suspension desulferization facilities of $75 \mathrm{t} / \mathrm{h}$ boiler. Electr. Power 35, 62-65 (2002) 
19. Li, Y., Tong, H., Ma, C., et al.: Analytic study on approach to adiabatic saturation temperature and the control scheme for the amount of water sprayed in the semi-dry FGD process. Fuel $\mathbf{8 3}$, 2255-2264 (2004). doi:10.1016/j.fuel.2004.06.013

20. Irabien, A., Cortabitarte, F., Ortiz, M.I.: Kinetics of flue gas desulfurization at low temperatures: nonideal surface adsorption model. Chem. Eng. Sci. 47, 1533-1543 (1992). doi:10.1016/00092509(92)85002-S

21. Li, G.G., Keener, T.C., Stein, A.W., Khang, S.J.: CO2 reaction with $\mathrm{Ca}(\mathrm{OH}) 2$ during $\mathrm{SO} 2$ removal with convective pass sorbent injection and high temperature filtration. Environ. Eng. Policy 2, 47-56 (2000)

22. Rahimi, A., Hatamipour, M.S., Gholami, M., Haghnegahdar, M.R.: Non-isothermal modeling of the flue gas desulphurization process using a semi-dry spouted bed reactor. Chem. Eng. Res. Des. 89, 777-784 (2011). doi:10.1016/j.cherd.2010.08.014
23. Scala, F., D'Ascenzo, M.: Absorption with instantaneous reaction in a droplet with sparingly soluble fines. AIChE J 48, 1719-1726 (2002). doi:10.1002/aic.690480813

24. Scala, F., D’Ascenzo, M., Lancia, A.: Modeling flue gas desulfurization by spray-dry absorption. Sep. Purif. Technol. 34, 143-153 (2004). doi:10.1016/S1383-5866(03)00188-6

25. Garea, A., Herrera, J.L., Marques, J.A., Irabien, A.: Kinetics of dry flue gas desulfurization at low temperatures using $\mathrm{Ca}(\mathrm{OH}) 2$ : competitive reactions of sulfation and carbonation. Chem. Eng. Sci. 56(4), 1387-1393 (2001). doi:10.1016/S0009-2509(00)00362-6

26. Marquardt, D.W.: An algorithmfor least-squares estimation of nonlinear parameters. J. Soc. Ind. Appl. Math. 11, 431-441 (1963). doi: $10.1137 / 0111030$

27. Neveux, T., Le Moullec, Y.: Wet industrial flue gas desulfurization unit: model development and validation on industrial data. Ind. Eng. Chem. Res. 50, 7579-7592 (2011). doi:10.1021/ie102239q 